\title{
Rhotics and Palatalization: An Acoustic Examination of Upper and Lower Sorbian
}

\author{
Phil Howson \\ Department of Linguistics, University of Toronto, Toronto, ON, Canada
}

\begin{abstract}
Two of the major problems with rhotics are: (1) rhotics, unlike most other classes, are highly resistant to secondary palatalization, and (2) acoustic cues for rhotics as a class have been elusive. This study examines the acoustics of Upper and Lower Sorbian rhotics. Dynamic measures of the F1-F3 and F2-F1 were recorded and compared using SSANOVAs. The results indicate there is a striking delay in achievement of F2 for both the palatalized rhotics, while F2, F1, and F2-F1 are similar for all the rhotics tested here. The results suggest an inherent articulatory conflict between rhotics and secondary palatalization. The delay in the F2 increase indicates a delay in the palatalization gesture. This is likely due to conflicting constraints on the tongue dorsum. There was also an overlap in the F2 and F2-F1 for both the uvular and alveolar rhotics. This suggests a strong acoustic cue to rhotic classhood is found in the F2 signal. The overall formant similarities in frequency and trajectory also suggest a strong similarity in the vocal tract shapes between uvular and alveolar rhotics.
\end{abstract}

(ㄷ) 2018 S. Karger AG, Basel

\section{Introduction}

Sorbian is an endangered West Slavic language spoken in Eastern Germany (Moseley, 2012). There are 2 primary dialects of Sorbian: Upper Sorbian - spoken near the border of the Czech Republic - and Lower Sorbian - spoken near the border of Poland (Stone, 1993; Howson, 2017). Upper Sorbian has adopted the uvular trill (Carlton, 1991), which is likely the result of exposure to German, yielding a plain and

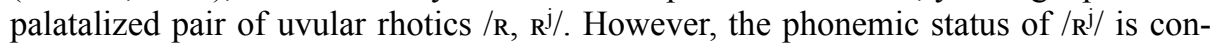
tentious and is not agreed upon by all researchers (Wornar, 2007; Jocz, 2013). Lower Sorbian, on the other hand, has retained the alveolar trills $/ \mathrm{r}, \mathrm{r} /$, which are common among the other Slavic languages. The fact that the dialects of Sorbian contain both uvular and alveolar rhotics makes them an excellent testing ground for the effects of secondary palatalization on rhotics. This provides an opportunity to not only test what unites the rhotics as a class, but also what acoustic/articulatory features - if any - are common across rhotics. This is of particular interest because it allows for a comparison

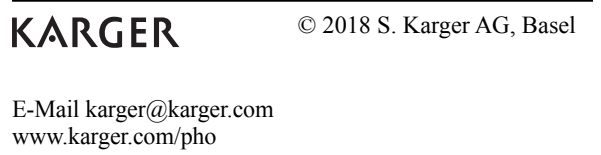

Phil Howson

Department of Linguistics, University of Toronto Sidney Smith Hall, 4th Floor

100 St. George Street, Toronto, ON M5S3G3 (Canada)

E-Mail phil.howson@mail.utoronto.ca 
of alveolar and uvular rhotics, the latter of which has, to the best of my knowledge, been omitted from most studies concerning the classhood of rhotics [see Lindau (1985) for acoustic analysis of alveolar and uvular rhotics].

\subsection{Rhotics}

Ladefoged and Maddieson (1996) state that sounds are typically categorized as belonging to a specific natural class based on articulatory or acoustic properties; rhotics, however, do not seem to have any consistent articulatory or acoustic properties. Ladefoged and Maddieson (1996) further describe the most prototypical members of the rhotics as being articulated with the tongue tip (IPA: r). The prototypical members of the class show phonological relationships with the other heterogeneous members of the class, which includes taps, fricatives and approximants. For example, rhotics have a diachronic tendency to undergo sound change from an approximant to a fricative [e.g., Proto-Slavic: $/ \mathrm{r}^{\mathrm{j} /} \rightarrow$ Czech: /r/, Polish /zl, Carlton (1991); Old-Sorbian: /tr/ $\rightarrow$ Lower Sorbian: /ts/, Schaarschmidt (1998)].

Based on the rhotics in Tamil, Narayanan et al. (1999) describe apical rhotics as being united in the overall tongue shape. An apical gesture creates a constriction with no medial tongue-palate contact, similar to vowels. There is also a concave tongue shape behind the constriction and a lack of a lateral channel. The uvulars, however, have a somewhat different articulatory profile. Delattre (1971) demonstrated that uvular trills begin with an initial retraction of the tongue root. The tongue body then rises towards the uvula and is then displaced forward to a position where trilling can occur. Ladefoged and Maddieson (1996) thus point out that articulatory characteristics do not seem to unite the class of rhotics. This leaves open the question of whether rhotics are united only in diachronic and synchronic phonological relationships or whether there is an articulatory or acoustic quality which has been missed. However, Ladefoged and Maddieson (1996) suggest that based on Lindau's (1985) work, the class feature for rhotics may be primarily acoustic or auditory in nature.

If the acoustic properties of rhotics are examined, lowered F3 is often touted as the defining characteristic of rhotics (Delattre and Freeman, 1968; Knight et al., 2007; Mielke, 2011), but previous studies (e.g. Lindau, 1985) have found that a lower F3 is actually uncommon cross-linguistically and that the majority of the world's languages do not make use of a lowered F3 to distinguish rhotics from other approximant sounds. This does raise the question of what acoustic or articulatory feature unites the rhotics as a natural class, if not lowered F3. The rhotics - as a class - also have another peculiar feature: secondary palatalization causes a delayed palatalization gesture which can be observed in the F2 formant dynamics (Spajić et al., 1996) and the articulatory gestures (Kochetov, 2005). However, the cause of this articulatory asymmetry is unclear and often results in a loss of palatalization as a secondary feature [e.g., Proto-Slavic: $/ \mathrm{r}^{\mathrm{j}} / \rightarrow$ Slovenian: /rj/, Slovak: /r/, Carlton (1991)].

Trills also make up a subclass of rhotics and are among the most common rhotics used in the world's languages [46.1\% of languages with rhotics employ a voiced trill, Maddieson (1984)]. Trills have tight constraints on the articulatory settings required to achieve the correct aerodynamics to facilitate trilling. That is to say, in order to create the aerodynamic conditions necessary for trilling, the tongue position requirements are extremely rigid, and failure to achieve the correct tongue shape results in the loss of trilling. McGowan (1992) cites lateral tongue bracing as an important factor for controlling the tongue stiffness, which allows aerodynamics to cause the tongue tip to

Rhotics and Palatalization in Upper and Lower Sorbian
Phonetica 2018;75:132-150

DOI: $10.1159 / 000481783$ 
vibrate. The tongue body movement is tightly constrained, while the tongue tip (in the case of apical trills) is left flexible, and as a result, trilling occurs. Precise control over the airflow and pressure is also required for trilling. Solé (2002) was able to show that small changes in oropharyngeal pressure result in the loss of trilling, due to a narrow range of permissible variation. The oropharyngeal pressure differences between trills and fricatives are also rather narrow. Solé (2002) suggests that these narrow margins account for the alternations between trills and fricatives.

Unifying representations of rhotics have been generally unsuccessful in accounting for the phonological variation and distribution across languages, especially for feature-based theories of phonology (Wiese, 2001) and acoustic models of rhotic (Ladefoged and Maddieson, 1996). Proctor $(2009,2011)$ proposed a gestural analysis of rhotics (and laterals) based on articulatory phonology (Browman and Goldstein, $1995)$. Proctor $(2009,2011)$ proposed that rhotics (and laterals) are united by a coordination of a tongue tip and tongue dorsum gesture. This model was used to account for Slavic liquid metathesis occurring due to a 180-degree phase shift between the tongue tip gesture and the tongue dorsum gesture. The result was a historical change from coda position liquids to an onset position [e.g. */orv-Inu/ "even" > /rov(e)n/, Proctor (2009, 2011)].

Other researchers have also suggested that apical rhotics are produced with tongue dorsum retraction (Recasens and Pallarès, 1999) and an apical tongue gesture (Catford, 1988; Recasens and Pallarès, 1999). Hall and Hamann (2010) suggest this creates a concave shape, which is characteristic of apical rhotics. The concave shape of rhotics has been attributed to the avoidance of rhotics and palatalization. Palatalization produces a "convex" (p. 1838) tongue shape which Recasens and Pallarès (1999) describe as antagonistic to rhotic articulation. This conflict has been suggested to be responsible for the cross-linguistic avoidance of rhotics and high vocoid sequences (Hall and Hamann, 2010). Both high front vocoids and rhotics have a high degree of resistance to coarticulation (Recasens, 1991; Recasens and Pallarès, 1999), especially in the region of the tongue dorsum. This creates complication between sequences of these sounds; it also highlights that a tongue dorsum gesture is a crucial feature of rhotics as a class.

The purpose of this study is thus twofold: (1) examine the acoustic effects of palatalization on both alveolar and uvular rhotics; (2) examine the acoustics of a number of rhotics to get a more accurate description of their characteristics. Many studies have examined alveolar rhotics (Westbury et al., 1995; Alwan et al., 1997; Iskarous and Kavitskaya, 2010), but few studies have looked at both uvular and alveolar rhotics at the same time. Upper Sorbian has uvular rhotics, $/ \mathrm{R}, \mathrm{R}^{\mathrm{j}} /$, and Lower Sorbian has alveolar rhotics, $/ \mathrm{r}, \mathrm{r} /$, which makes Sorbian an excellent testing ground for an analysis of the characteristics of rhotics and secondary palatalization of rhotics. Sorbian is unique in having a phonemically palatalized uvular rhotic, which is unattested in any other language; therefore, examining it in context with other rhotics has the potential to help draw more significant generalizations about rhotics and the secondary palatalization of rhotics.

\subsection{Previous Studies on Rhotics and Palatalization}

While the examinations of rhotics by Lindau (1985) and Alwan et al. (1997) were quite comprehensive, they did not include an examination of palatalized rhotics. However, a noteworthy acoustic study on the plain and palatalized contrast in alveolar trills was performed by Iskarous and Kavitskaya (2010). The use of acoustic measures 
was due to the fact that there is a complex interaction between the dorsal gesture of adjacent vowels and tongue body gestures associated with palatalization. Specifically, they used an F2-F1 measure taken at different points during articulation. The F2-F1 measure was adopted from Sproat and Fujimura (1993), who used X-ray microbeam and acoustics to examine the articulation of the lateral /1/ in English. Their findings suggested that the F2-F1 measure correlated strongly with the backing of the tongue [see also Fant (1960)].

The findings from Iskarous and Kavitskaya's (2010) study of Russian indicated that $/ \mathrm{r}^{\mathrm{j}} /$ is most commonly realized as a tap $(1 \%$ of the time it was a full trill - i.e. the trill had multiple contacts), while $/ \mathrm{r} /$ was realized as a full trill $26 \%$ of the time. This suggests the realization of both of the trills is different. The trills were more often articulated as an approximant. Word-initial positions had a higher chance of having multiple contacts for both of the trills, with word-final position being the next most likely position. The duration of the trill impacted whether or not it was realized with multiple contacts. It was shown that the longer the duration, the more likely it was realized with multiple contacts.

The acoustic measures from Iskarous and Kavitskaya's (2010) study showed that the palatalized trills showed a general increase in F2 by about $130 \mathrm{~Hz}$ throughout the duration of the trill, relative to the $\mathrm{F} 2$ at the beginning of $/ \mathrm{r} /$. This effect was best detected in preceding vowels, which also showed the steady increase in F2. The findings suggested that the physiological constraints on palatalized rhotics do not prohibit co-articulatory or prosodic variability. This is due to the fact that the F2-F1 measure showed significant variation across the word positions examined. That is to say, each of the preceding and following vowels affected the beginning and end point of the trills differently. Finally, the secondary articulation was apparent in all word positions. This was especially unexpected for the intervocalic position where Lindblom [1963] would expect a significant undershoot in the gestural target [see Lindblom (1963) for a discussion of the undershoot hypothesis]. This is largely due to the shorter duration, which would cause the gestures to fail to reach their targets before transitions to the following vowels. The primary issue is that it would interfere with the secondary articulation. The failure to fully reach the target for secondary articulation would cause it to more likely be lost in word medial position. The authors explain that because the intervocalic position causes a longer tongue body gesture, it increased the duration of the trill, maintaining the contrast between the trills. The authors also suggest that the palatalization gesture reduces the ability to achieve the apical gesture through reduced retraction or it affects the ability to control the stiffness and inertia of the tongue, which helps achieve the strict aerodynamic conditions necessary for trilling [discussed in McGowan (1992) and Solé (2002)].

Iskarous and Kavitskaya (2010) explain that the delayed increase in F2 in the onset position is in line with Sproat and Fujimura's (1993) suggestion that the vocalic gesture is attracted to the vocalic center. A primary issue is that Iskarous and Kavitskaya (2010) note that the F2 increase is greater in intensity in the coda, which is unexpected under the assertion of Sproat and Fujimura (1993) that vocalic gestures are attracted to the vocalic centre. This leaves open the question of why the delay in F2 occurs and more specifically why it is more prevalent among rhotics.

A Dravidian language with a large liquid inventory is Toda, which boasts 8 liquid segments: 2 laterals $/ 1, l /$ and 6 trills, which are comprised of 3 phonemically palatal-

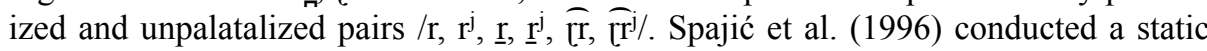


palatography and acoustic study of the 6 contrastive trills in Toda. The primary issues the authors investigated were whether or not the contrast between trills is in fact 6-way and whether the trills are made with multiple contacts or if they are simply taps. Six male speakers of Toda participated in the study. The findings indicated that the dental rhotic has a lower F1 and higher F2 than the alveolar rhotic. This suggested that the primary contrast between the 2 was not place of articulation, but rather whether the tongue dorsum was advanced or retracted. The retroflex had the lowest F3 at the onset of the rhotics, which is likely a key point of contrast. They also found that all the palatalized counterparts had a steadily rising F2 from the onset of the preceding vowel through the off-glide. This led the authors to conclude that there are in fact 6 phonemically contrastive trills in Toda.

The delayed increase in F2 in Toda and Russian has also been observed directly with articulatory measures. Kochetov's (2005) study of Russian liquids $-/ \mathrm{r} \mathrm{r}^{\mathrm{j}} 1 \mathrm{l}^{\mathrm{j} /}-$ using electromagnetic articulography revealed a striking contrast between the rhotics and laterals: there was a significant lag between the onset of the rhotic articulation and the tongue body gesture associated with secondary palatalization. However, the palatalized lateral did not show this trend. Stoll et al. (2015) had similar findings with their electromagnetic articulography study of Russian liquids. The tongue tip achieved its target much sooner than the tongue body in the case of the palatalized rhotic in word-initial and word-final position. The palatalized lateral did not exhibit this effect, with nearly simultaneous achievement of the tongue tip and tongue body gestures. This effect was not observed word-medially, where both rhotics and laterals exhibited near simultaneous achievement of the tongue tip and tongue body gesture. The speech rate did not affect any of these results.

\subsection{Hypotheses}

There are 2 hypotheses that this paper will test based on the previous literature. (1) There will be a discernible delay in the peak F2 achievement for both apical and uvular palatalized rhotics. (2) Despite being different places of articulation, both the alveolar and uvular rhotics have similar formant frequencies and trajectories for F1, F2, and F2-F1.

For hypothesis 1, the expectation for a delay in an increase in F2 as a result of secondary palatalization for rhotics follows other studies which have correlated the 2 together [e.g. Spajić et al. (1996) or Kochetov (2005)]. Thus, a delay in the peak of F2 should obtain for both alveolar and uvular rhotics. Kochetov (2005) and Stoll et al. (2015) have also correlated the delayed increase in F2 observed in rhotics with a delay in the palatalization gesture for rhotic segments. Therefore, a delay in F2 for Sorbian rhotics is likely to correlate with a delay in the palatalization gesture.

Hypothesis 1 is rooted in previous acoustic and articulatory work which suggests that secondary palatalization and rhotics involve inherently antagonistic gestures. Spajić et al. (1996) and Iskarous and Kavitskaya (2010) both found a delayed increase in F2 for palatalized rhotics (in Toda and Russian, respectively). This delay has been connected specifically to rhotics as opposed to other palatalized segments (Kochetov, 2005). This is likely the acoustic consequence of an inherent instability in the production of palatalized rhotics. Kavitskaya et al. (2009) suggest that this instability originates with an inherent conflict between the tongue dorsum during rhotic production and secondary palatalization. Rhotic production requires tongue dorsum retraction, while secondary palatalization requires tongue dorsum fronting. If this is the case, we 
expect to see a delay in the increase of F2 and F2-F1 when secondary palatalization occurs with rhotics. The hypothesis relates to the vocalic tongue dorsum gesture, which Proctor $(2009,2011)$ posits as one of the primary components of rhotic production. This results in an inherent conflict in the target and dynamics between rhotic production and secondary palatalization.

Hypothesis 2 follows from previous acoustic and articulatory work. Heselwood (2009) performed a perceptual identification experiment which consisted of the English rhotic with F3 removed in a variety of words. The results showed that participants were better at identifying the rhotic without the presence of F3 than with it. The authors suggest that F2 may be the primary acoustic correlate to rhotic classhood (in English). Engstrand et al. (2007) also performed a perceptual study of rhotics, focusing instead on alveolar and uvular variants. The experiment manipulated the F2 and F3 formant structure on a continuum from prototypically alveolar to prototypically uvular for Swedish speech. Swedish listeners participated in the study and the results for the discrimination task indicated that correct identification as alveolar or uvular was rarely above chance at any point of the continuum. This suggests an overall similarity in formant structure between the alveolar and uvular rhotics.

Previous articulatory data also suggest an articulatory similarity across places of articulation. Narayanan et al. (1999) suggested that the coronal rhotics in Tamil are all united by a similar concave tongue shape. While the uvular rhotic has not been examined specifically in this context, the expectation is that there are strong similarities in overall vocal tract shape between the alveolar and uvular rhotics. This should be observed in the acoustics as an overall similarity between the formant dynamics and frequencies, most specifically F1, F2, and F2-F1. If a similarity in the formants and trajectories is found, this would suggest a corresponding similarity in the vocal tract shape created by the tongue dorsum, specifically in the area of the soft palate and the pharynx.

Proctor $(2009,2011)$ suggests that rhotics are linked by the coordination of the tongue dorsum and tongue tip gestures. If Proctor's $(2009,2011)$ analysis is on the correct path, it is expected that there should be striking similarities between the formants and their dynamics for both the uvular and alveolar rhotic. Furthermore, if the analysis of Tamil rhotics by Narayanan et al. (1999) extends to other languages and places of articulation, we would expect to see similar acoustics between the uvular and alveolar rhotic. The assumption here is essentially that a uvular rhotic is composed of a strong dorsal component, like the alveolars, but lacks the coronal gesture. The dorsal component accompanied by a lack of a coronal gesture is still expected to create a similar vocal tract shape which would be reflected in the acoustics. Specifically, the expectations are that F2 and F2-F1 should share similar formant frequencies and trajectories between the 2 places of articulation as they correlate most strongly with the activity of the tongue dorsum [especially F2-F1; see Sproat and Fujimura (1993)].

\section{Methods}

\subsection{Speakers}

Six native speakers of Upper Sorbian ( 3 male and 3 female) were recorded in a sound-attenuated booth at the Max Planck Institute for Evolutionary Anthropology. Three other native speakers of Upper Sorbian (3 female) were also recorded in a quiet room in Bautzen. Five native speakers of

Rhotics and Palatalization in Upper and Lower Sorbian
Phonetica 2018;75:132-150

DOI: $10.1159 / 000481783$ 
Table 1. The Sorbian word sets used in this study

\begin{tabular}{|c|c|c|c|c|}
\hline & Upper Sorbian & & Lower Sorbian & \\
\hline $\mathrm{R}$ & rad & "gladly" & & \\
\hline$R^{j}$ & rjadka & "line, verse" & & \\
\hline $\mathrm{r}$ & & & rada & "recommendation" \\
\hline$r^{j}$ & & & rjagotaś & "to stutter" \\
\hline 1 & lac & "waistcoat" & lac & "vest (dim)" \\
\hline
\end{tabular}

Lower Sorbian ( 2 male and 3 female) were recorded in a quiet room in Cottbus. All locations were within Lusatia, the Sorbian-speaking region of eastern Germany. There was a total of 8 Upper Sorbian participants and 5 Lower Sorbian participants (in total 13 participants).

\subsection{Procedure}

The recordings of the Upper Sorbian participants at the Max Planck Institute for Evolutionary Anthropology were all done using an Audix HT5P microphone at 44,100 Hz and 32 bits. All the data recorded in the field were taken with a Fostex FR-2 LE Field Recorder and a Lavalier AT831b microphone at $44,100 \mathrm{~Hz}$ and 32 bits.

\subsection{Materials}

Participants repeated a corpus of real words which was comprised of each rhotic and lateral in a word-initial position (Table 1) followed by the low vowel /a/. The Upper Sorbian data set contained words with the liquids $/ \mathrm{R}, \mathrm{R}^{\mathrm{j}}, 1 /$. Each word was produced 3 times by each speaker for a total of 72 tokens ( 3 repetitions of each word $\times 3$ words $\times 8$ speakers). The Lower Sorbian data set contained words with the liquids $/ \mathrm{r}, \mathrm{r}^{\mathrm{j}}, 1 /$. Each word was produced 3 times by each speaker for a total of 45 tokens ( 3 repetitions of each word $\times 3$ words $\times 5$ speakers). Low F3 has been described as characteristic of rhotics (Delattre and Freeman, 1968), but not laterals; therefore, /1/ was included in both data sets in order to compare the F3 of both alveolar and uvular rhotics against a lateral to determine if it does distinguish rhotics from laterals.

The total number of tokens recorded is somewhat small, but the data presented here provide a unique insight into an understudied language with little phonetic work done on it. The acoustic analysis of Upper and Lower Sorbian allows a comparison of alveolar and uvular rhotics, both of which have plain and palatalized phonemes. This allows for documentation of an endangered language, while also permitting significant generalizations about rhotics and palatalized rhotics.

\subsection{Analysis}

The analysis is composed of 2 different observations with different statistical measures applied to them: (1) SSANOVA (smoothing spline analysis of variance) measures of the formants F1-F3 and F2-F1 for the rhotics (and the plain lateral /1/), presented in section 3.1 and (2) a $\chi^{2}$ test comparing the realizations of the rhotics as either a trill or approximant, presented in section 3.2.

Dynamic measures were taken for F1-F3 at 10 equally spaced intervals for the entire liquid up to the temporal mid-point for the following vowel (Fig. 1). This created an interpolated time for the dynamic measures analysis. The formant measures were extracted using Praat (Boersma and Weenink, 2014) and were normalized using a Lobanov correction (Lobanov, 1971; Adank et al., 2004) with the Vowels package (Thomas and Kendall, 2007) in R (R Development Core Team, 2016). F2-F1 (Sproat and Fujimura, 1993) was calculated by subtracting F1 from F2. The formant measures were then compared using an SSANOVA (Gu, 2002; Davidson, 2006) in R (R Development Core Team, 2016). SSANOVA mean curves were based on input splines. Bayesian confidence intervals were then calculated to locate areas of statistically significant difference along the 2 (or more) curves (Davidson, 2006). Liquids were grouped according to dialect (Upper Sorbian, 3 levels: /R, $\mathrm{R}^{\mathrm{j}}, 1$; , Lower Sorbian, 3 levels: /r, $\mathrm{r}^{\mathrm{j}}, \mathrm{1} /$ ). The factor for comparison was liquid identity (Upper Sorbian: /R, $\mathrm{R}^{\mathrm{j}}, 1 /$; Lower Sorbian: $\left./ \mathrm{r}, \mathrm{r}^{\mathrm{j}}, \mathrm{l} /\right)$. 


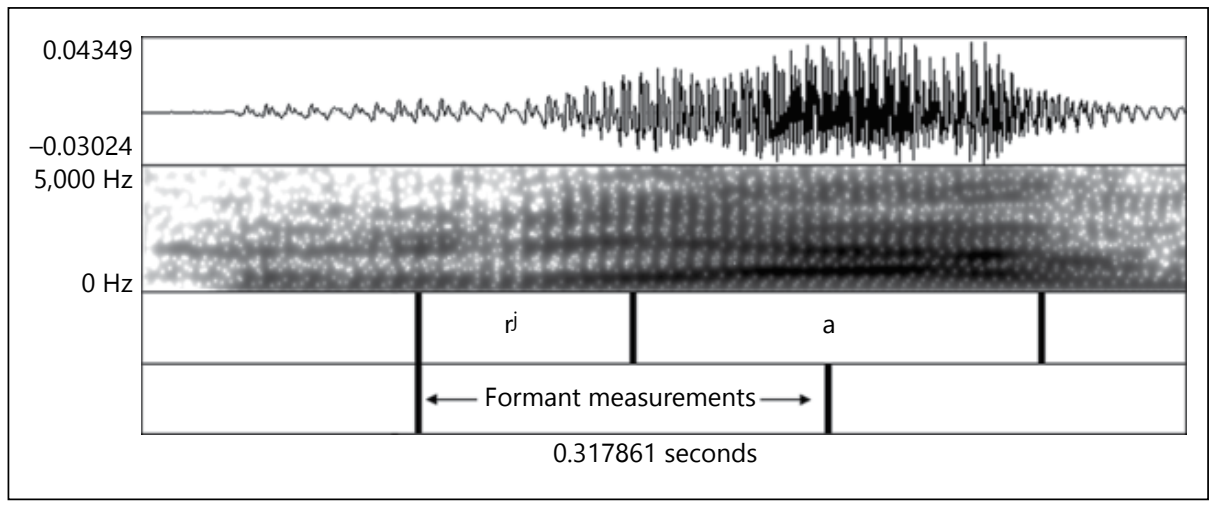

Fig. 1. Formant measures were taken from the onset of the rhotic to the mid-point of the vowel. The image shows $\left[\mathrm{r}^{\mathrm{j}} \mathrm{a}\right]$ from the Lower Sorbian word rjagotaś "to stutter."

A count of the number of realizations of the plain and palatalized rhotics as either approximants or trills was also taken. That is to say, a count was made as to whether there were tongue-palate contacts during the production of the plain and palatalized rhotics for both Upper and Lower Sorbian. Following the methods in Iskarous and Kavitskaya (2010), the presence of an occlusion in the spectrogram was taken to indicate a contact (trill realization) and the absence of a spectral occlusion was taken to indicate no contact (approximant realization). The results were compared statistically using a $\chi^{2}$ goodness-of-fit comparison in R (R Development Core Team, 2016).

\section{Results}

In this section, the results for dynamic measures (section 3.1), followed by the counts of realizations as trill or approximant (section 3.2) are presented. The Upper Sorbian data are presented, followed by the Lower Sorbian data. Then the results of the count of realizations of each of the trills are presented, followed by the dynamic analysis.

\subsection{Dynamic Results}

The results presented here show the dynamics of the formants for the liquid and the transition into the following vowel, up to the mid-point of the following vowel. An SSANOVA plot is made up of 2 main components: the average curve and the $95 \%$ confidence intervals. The solid lines indicate the mean curve for each of the formants and F2-F1. The dotted lines surrounding the mean indicate the $95 \%$ confidence intervals. If the dotted lines for 2 (or more) means do not cross at a particular point, the point is considered to be a location of statistically significant difference.

\subsubsection{Upper Sorbian}

Figure 2 presents the results of the dynamic analysis of the Upper Sorbian liquids. The results for the dynamics of F1-F3 are presented in Figure 2a, and the results for the dynamics of F2-F1 are presented in Figure $2 \mathrm{~b}$.

The formant trajectories for $/ \mathrm{R} /$ indicated a relatively steady decrease in F2 over the duration of its articulation and during the following vowel, while F1 showed a steady rise for the following vowel /a/. Both F1 and F2 for /R/ were significantly different 


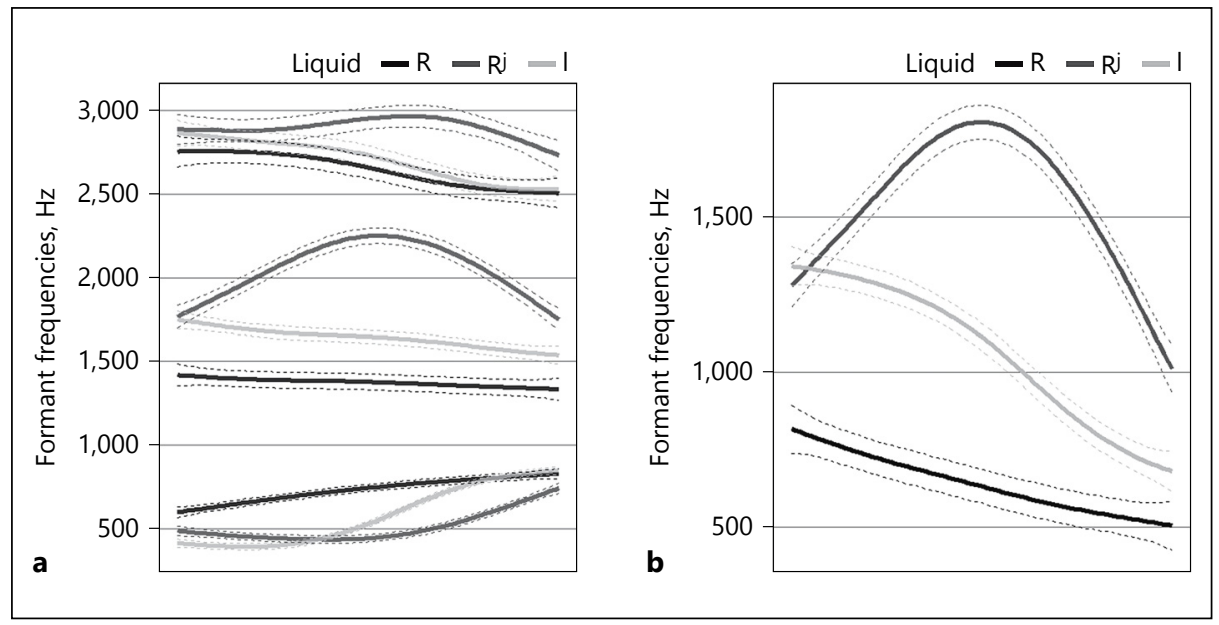

Fig. 2. Formant (a F1-F3; b F2-F1) dynamics of the Upper Sorbian liquids. The left edge indicates the onset of the liquid, and the right edge of the graph indicates the mid-point of the vowel /a/.

from $/ \mathrm{R}^{\mathrm{j} /}$ for the entire duration. For $/ 1 /, \mathrm{F} 1$ and F2 were also significantly different from $/ \mathrm{R}^{\mathrm{j} /}$ except that the difference in $\mathrm{F} 1$ for the vowel following both $/ \mathrm{R}, 1 /$ became nonsignificant after the transitions for $/ 1 / . / \mathrm{R}^{\mathrm{j}} /$ had a lower $\mathrm{F} 1$ than $/ \mathrm{R} /$ and was briefly higher than $/ 1 /$ during articulation of the liquid. F2 was higher for $/ \mathrm{R}^{\mathrm{j}} /$ than $/ \mathrm{R}, 1 /$ but started at the same frequency as $/ 1 /$. The off-glide following $/ \mathrm{R}^{\mathrm{j}} /$ resulted in a sharp rise in $\mathrm{F} 2$, which was then followed by a sharp drop towards the target for /a/. F1 was lower for /1/ than both trills, but showed a sharp increase for the transition to the following vowel. $\mathrm{F} 2$ for /1/ showed a steady decrease over the duration.

The F3 trajectory for /R/ showed a brief period of difference from /1/ during articulation of the liquid, but this difference is lost during the transition into the following vowel. $\mathrm{F} 3$ for $/ \mathrm{R}^{\mathrm{j}} /$ was not significantly different from $/ \mathrm{R} /$ or $/ \mathrm{l} /$ during the majority of the duration of the liquid; however, F3 rose sharply before dropping again after F2 began to fall, separating it from /R, 1/. The F3 rise was not as dramatic as F2 either. F3 for $/ \mathrm{l} /$ was significantly different from $/ \mathrm{R} /$ during the articulation of the liquid, but the formant transitions into the vowel caused a drop in $\mathrm{F} 3$, resulting in it meeting with $/ \mathrm{R} /$, but diverging from $/ \mathrm{R}^{\mathrm{j}}$.

The dynamics of the F2-F1 measure indicated that the trajectory of $/ \mathrm{R} /$ was lower than $/ 1 /$ and $/ \mathrm{R}^{\mathrm{j}} /$ for the entire duration until it meets with $/ 1 /$ at the mid-point of the vowel. The F2-F1 trajectory for $/ \mathrm{R}^{\mathrm{j}} /$ began as high as $/ 1 /$ and continued upwards for the duration of the off-glide and then fell sharply. $/ \mathrm{R}^{\mathrm{j}} /$ had a large difference between $\mathrm{F} 1$ and $\mathrm{F} 2$ causing it to be higher than $/ \mathrm{R} /$ and $/ \mathrm{l} /$ even by the mid-point of the vowel. $/ \mathrm{l} /$ began with the same difference in $\mathrm{F} 2-\mathrm{F} 1$ as $/ \mathrm{R}^{\mathrm{j}} /$, but had a different dynamic trajectory. F2-F1 for /1/ quickly began to drop in order to reach the target for /a/, causing it to meet with $/ \mathrm{R} /$ at the mid-point of the vowel.

The formant trajectory for each of the liquids was different, which likely reflects differences in place and tongue posture. These differences exerted different effects on the vowels following each liquid. Palatalization had a particularly strong effect on the following vowel, causing differences in F1 and F2, even at the mid-point of the vowel. 


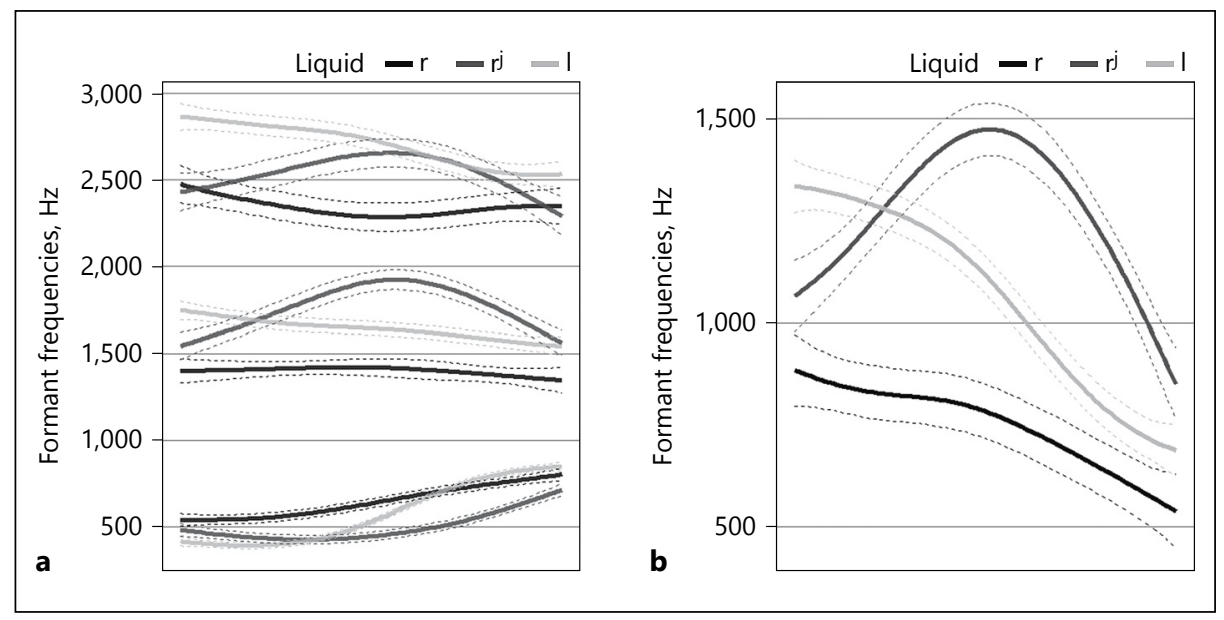

Fig. 3. Formant (a F1-F3; b F2-F1) dynamics of the Lower Sorbian liquids. The left edge indicates the onset of the liquid, and the right edge of the graph indicates the mid-point of the vowel /a/.

\subsubsection{Lower Sorbian}

Figure 3 presents the results of the dynamic analysis of the Lower Sorbian liquids. The results for the dynamics of F1-F3 are presented in Figure 3a, and the results for the dynamics of F2-F1 are presented in Figure 3b.

$\mathrm{F} 1 \mathrm{for} / \mathrm{r} /$ steadily rose throughout articulation and during the following vowel. It remained statistically lower than the other 2 liquids until much closer to the midpoint of the vowel where the F1 for all 3 liquids started to converge. F2 remained stable over the duration of the liquid and vowel, lowering only slightly. F1 for $/ \mathrm{r}^{\mathrm{j}} /$ began lower than $/ \mathrm{r} /$ and increased over the course. It remained lower than $/ \mathrm{r}, 1 /$ even at the mid-point of the following vowel. F2 for $/ \mathrm{r}$ / began higher than $/ \mathrm{r} /$ and rose during the off-glide following the trill, and then dropped towards the mid-point of the vowel, remaining higher than $/ \mathrm{r} /$. The F2 was higher for $/ 1 /$ than $/ \mathrm{r} /$ and remained that way over the duration. F2 was relatively stable the entire time for both $/ \mathrm{r} /$ and $/ 1 /$.

$\mathrm{F} 3$ for $/ \mathrm{r} /$ and $/ \mathrm{r}^{\mathrm{j}} /$ began at the same relative formant frequency, lower than for the lateral. However, $/ \mathrm{r} /$ and $/ \mathrm{r}^{\mathrm{j}} /$ quickly diverged as the off-glide for $/ \mathrm{r}^{\mathrm{j}} /$ causes an upwards formant trajectory. F3 for /r/ lowered, causing it to be lower than the other 2 liquids. The formant frequency and trajectories for F3 of the lateral were higher than those of the rhotics, although it takes a downward trajectory, which eventually meets with $/ \mathrm{r} /$, but remains higher than the rhotics at the mid-point of the vowel.

$\mathrm{F} 2-\mathrm{F} 1$ for $/ \mathrm{r} /$ remains significantly lower than $/ \mathrm{r}^{\mathrm{j}} /$ and $/ 1 /$ during the entire duration and has a downward trajectory. F2-F1 for $/ \mathrm{r}^{\mathrm{j}} /$ began higher than $/ \mathrm{r} /$ and then had an upward trajectory during the off-glide. It then fell again towards the mid-point of the vowel. However, it was still higher than for the other liquids by the mid-point, suggesting palatalization causes a substantial fronting effect of the following vowel. F2-F1 for $/ \mathrm{l} /$ began higher than $/ \mathrm{r} /$ but had a downward trajectory, causing it to lower as far as $/ \mathrm{r} /$ by the mid-point of the vowel. The difference between $/ 1 /$ and the rhotics remained significant for the duration of production. 


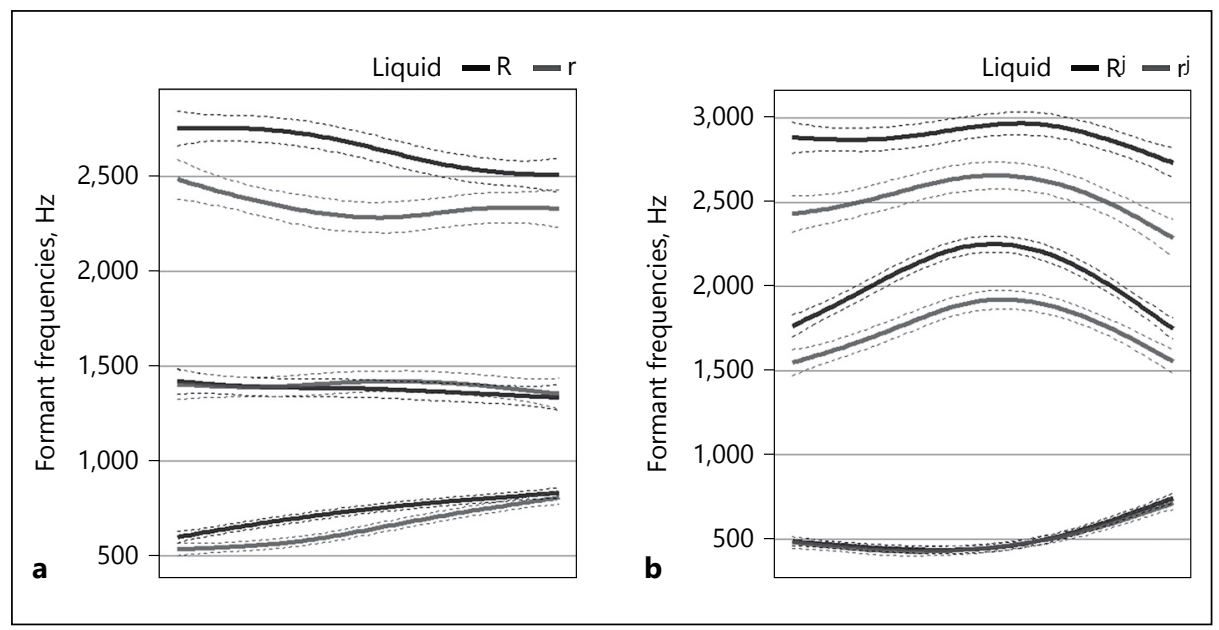

Fig. 4. Comparison of the F1, F2 and F3 for plain (a) and palatalized (b) trills in Upper and Lower Sorbian.

\subsubsection{Comparison of Upper and Lower Sorbian}

Figure 4 presents direct comparisons of the plain and palatalized rhotics in Upper and Lower Sorbian. These figures are presented here in order to facilitate ease of discussion about the similarities between uvular and alveolar rhotics.

$\mathrm{F} 1$ for $/ \mathrm{r} /$ was slightly lower than that for $/ \mathrm{R} /$ for the duration of the rhotic production and most of the following vowel. Both $/ \mathrm{r} /$ and $/ \mathrm{R} /$ showed an increasing trajectory for F1, until the mid-point of the following vowel. It should be noted that while these differences are significant, the absolute value of the difference in hertz is relatively small, within approximately $100 \mathrm{~Hz}$ at its largest point of difference. However, F2 showed no significant difference between $/ \mathrm{r} /$ and $/ \mathrm{R} /$. The trajectories and formant frequencies overlap for the entire duration of production. F3 is a marked point of difference between $/ \mathrm{r} /$ and $/ \mathrm{R} /$. F3 for $/ \mathrm{R} /$ is significantly higher than $/ \mathrm{r} /$ throughout the duration of articulation and remains significantly higher until the mid-point of the vowel. Both $/ \mathrm{r} /$ and $/ \mathrm{R} /$ have a dropping F3 over the duration of articulation, although the actual trajectories do differ to some degree. $/ \mathrm{R} /$ remains high for slightly longer during the rhotic, before dropping, while /r/ drops much more quickly and slightly increases into the mid-point of the vowel.

Both of the palatalized rhotics, $/ \mathrm{r}^{\mathrm{j}}, \mathrm{R}^{\mathrm{j}} /$, show identical frequencies and trajectories for F1. However, F2 and F3 differ in absolute hertz values. Although the formant frequencies are different, the trajectories share a striking number of similarities. Both $/ \mathrm{r}^{\mathrm{j} /}$ and $/ \mathrm{R}^{\mathrm{j} /}$ have a delayed increase in $\mathrm{F} 2$ which peaks at approximately the same time before dropping again into the mid-point of the vowel. F3 also has a steady increase and an eventual peak close to the same point as the peak in F2. However, $/ \mathrm{r}$ / has a short area of a steady F3 before it peaks and falls again.

\subsection{Measures of Realizations as Trills or Approximants}

An analysis of the number of realizations of each trill as full trill (multiple contacts), single contact trill, or an approximant was performed. The $\chi^{2}$ goodness-of-fit test 
Table 2. Count for the realization of each trill

\begin{tabular}{lcccc}
\hline & Multiple contacts & Single contact & Approximant & Total \\
\hline $\mathrm{R}$ & 2 & 12 & 10 & 24 \\
$\mathrm{R}^{\mathrm{j}}$ & 1 & 7 & 16 & 24 \\
$\mathrm{r}$ & 11 & 4 & 0 & 15 \\
$\mathrm{r}^{\mathrm{j}}$ & 0 & 11 & 4 & 15 \\
\hline Total & 14 & 34 & 30 & \\
\hline
\end{tabular}

Table 3. Residuals from the $\chi^{2}$ test

\begin{tabular}{lccc}
\hline & Multiple contacts & Single contact & Approximant \\
\hline $\mathrm{R}$ & -1.1119 & 0.4756 & 0.2531 \\
$\mathrm{R}^{\mathrm{j}}$ & -1.5937 & -1.0702 & 2.2280 \\
$\mathrm{r}$ & 5.0631 & -0.9927 & -2.4019 \\
$\mathrm{r}^{\mathrm{j}}$ & -1.6408 & 1.7448 & -0.7365 \\
\hline
\end{tabular}

was used with each row corresponding to each realization (6 levels: r-multiple contact, r-single contact, r-approximant, R-multiple contact, R-single contact, R-approximant) and columns corresponding to plain or palatalized ( 2 levels: plain, palatalized). The test revealed a significant difference in the realization of each trill $\left[\chi^{2}(6)=48.85, p<\right.$ 0.0001]. See Table 2 for a recount of the results and Table 3 for the residuals from the $\chi^{2}$ test.

The results indicate that $/ \mathrm{R} /$ deviates most significantly from the expected number of realizations for multiple contacts if the distribution was due to chance. $/ \mathrm{R} /$ is realized as a full trill (multiple contacts) less frequently and is most commonly realized with a single contact. $/ \mathrm{R}^{\mathrm{j}} /$ shows a different direction than $/ \mathrm{R} /$ with respect to the number of realizations as an approximant: it is realized far more frequently as an approximant. $/ \mathrm{r} /$ is realized most frequently as a full trill, which is also the greatest deviation from a distribution based on chance for all the rhotics. $/ \mathrm{r}^{\mathrm{j}} /$ was realized as a single contact far more frequently and never as a full trill. The pattern for $/ \mathrm{r}, \mathrm{r}^{\mathrm{j}} /$ is the same as observed by Iskarous and Kavitskaya (2010): / $\mathrm{r}$ / is more commonly realized as a multiple con-

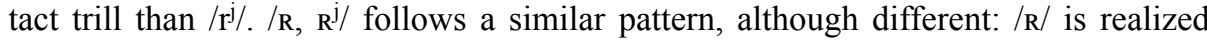
more commonly as a single contact trill than $/ \mathrm{R}^{\mathrm{j}} /$, which in turn is more commonly an approximant.

\section{Discussion}

This section will first discuss the interaction of palatalization and trills (section 4.1). How the results relate to the first hypothesis will be discussion in section 4.1.1 and the wider implication for these results will be discussed in section 4.1.2. The section following will discuss the rhotics as a natural class (section 4.2). The second hypothesis will be addressed in section 4.2.1, and the implications for rhotics as a class will be discussed in section 4.2.2. 


\subsection{Palatalization and Trills}

4.1.1 Hypothesis 1: A Delayed F2 for Palatalized Rhotics

This study examined the dynamic formant frequencies for palatalized rhotics in Upper and Lower Sorbian. The results revealed that during production of the palatalized rhotics there was a delayed increase in F2 that fell during vocalic transition, while the unpalatalized rhotics maintained a fairly steady F2 during production and into the following vowel. These results are similar to the findings of Spajić et al. (1996) for the palatalized rhotics and unpalatalized rhotics in Toda.

Overall, this verifies the hypothesis that the palatalized rhotic will exhibit a delay in F2 increase. Kochetov (2005) and Stoll et al. (2016) both found that in Russian there is a delay for the tongue body gesture associated with secondary palatalization. It is likely that this is the same for Sorbian: the tongue body advances and rises after the onset of the rhotic, causing a delayed increase in F2.

\subsubsection{Implications for the Dispreference between Rhotics and Palatalization}

There have been a few conflicting theories on why palatalization disprefers trills. Ladefoged and Maddieson (1996) suggest that the tongue blade is unbraced, which causes a larger vibrating mass. This creates a less favourable aerodynamic environment for trilling. Iskarous and Kavitskaya (2010) suggest that there are 2 possible reasons that trilling and palatalization are incompatible: palatalization may cause a retraction of the tongue tip gesture or decrease the ability to control the stiffness and inertia required to produce trilling. Hall (2000) also suggests that the (apical) feature found on alveolar rhotics is not compatible with the (distributed) feature which is accompanied with palatalization. Kavitskaya et al. (2009) and Hall and Hamann (2010) both suggest that there is an inherent conflict in the tongue shapes of rhotics and secondary palatalization. However, it is still not fully clear why palatalized rhotics are typologically marked.

The fact that the palatalized uvular trill exhibits the same formant dynamics as the alveolar trill for both F1-F3 and F2-F1 suggests that the tongue tip gesture is not the main force for the inconsistency between palatalization and trilling due to a complete lack of an apical gesture. However, the apical gesture may still be a factor. Iskarous and Kavitskaya's (2010) suggestion is also against Bolla's (1981) and Ladefoged and Maddieson's (1996) findings, which show tongue tip advancement for the palatalized trill. The temporal instability of F2 and F2-F1 is observed in both uvular and alveolar trills and suggests that the inconsistency between palatalization and trills is more likely related to aerodynamic factors, which Ladefoged and Maddieson (1996) also suggest. Iskarous and Kavitskaya (2010) make their claim partially based on the realization of the Russian trills as either full trills or single contact trills. They found that $/ \mathrm{r} /$ is realized more frequently as a full trill, while $/ \mathrm{r}^{\mathrm{j}} /$ is more frequently realized as single contact. This also seems to be the case for the trills in Lower Sorbian. The Upper Sorbian trills show a different, but similar pattern: $/ \mathrm{R} /$ is most often realized as a single contact, while $/ \mathrm{R}^{\mathrm{j}} /$ is most often realized as an approximant. This suggests that uvular trills are less likely to be realized as a full trill than alveolar trills are. However, the palatalization gesture still affects the uvular trill in a similar way: it reduces the realizations as a trill and in the case of an already reduced number of full trills, it causes more approximant realizations.

The trilling of the tongue is always realized prior to the full realization of the offglide, even though there is always a constant articulatory gesture towards this target. The gestural target for palatalization likely interferes with the aerodynamic conditions 
and tongue stiffness required to produce trilling. This suggestion follows from the constantly increasing F2 and F2-F1 over the duration of both the alveolar and uvular palatalized rhotic. The tight constraints on trill production could interfere with the palatalization gesture, which causes a delay in the movement to the palatal target. It is surmised that only after the trilling is complete can the palatalization target be fully achieved. The increase in palatalization causes an increasingly tight constriction in the palatal region, resulting in a Bernoulli effect (Kochetov and Howson, 2015). This causes a drop in air pressure, which Solé (2002) has shown causes a loss of trilling. Thus, this suggests an inherent conflict between the physical conditions necessary to produce trilling and the gestural coordination of secondary palatalization. The physical requirement for a strong degree of tongue stiffness and stability has been suggested by previous authors (McGowan, 1992; Ladefoged and Maddieson, 1996), which permits the flexible portion of the tongue to be limited to the tongue tip (in the case of the alveolar trill). This in turn, reduces the vibrating mass, causing trilling to be much easier to achieve. The palatal target likely reduces the ability to achieve proper tongue stiffness and aerodynamics and is thus delayed to permit trilling.

\subsection{Discussion of Rhotics as a Class}

4.2.1 Hypothesis 2: Alveolar and Uvular Rhotics Have Similar Formant Patterns

The dynamic formant frequencies of palatalized and unpalatalized rhotics were compared in Upper and Lower Sorbian. The results revealed a similar formant trajectory for F2 of the palatalized rhotics and an overlapping formant trajectory and frequency for F1. F3 also shared a similar trajectory, but differed in frequency. The unpalatalized rhotics differed slightly in F1 frequency and trajectory, but F2 overlapped in both frequency and trajectory. F3 has a similar trajectory, but differed in frequency.

Overall, this suggests significant overlap in the formant structure for alveolar and uvular rhotics. F2 is nearly identical, and the dynamics across all of the first 3 formants is similar. This does suggest some similarities in the vocal tract cavity which would facilitate not only the similarities in formant frequencies, but also in their dynamics. The strong similarities in F2 might actually correlate with an acoustic/articulatory cue for rhotics as a class, as Heselwood (2009) suggests based on perceptual data of English. The specific gestures/vocal tract shape associated with the F2 still need to be investigated further, but this does suggest some overarching similarity in rhotic production.

\subsubsection{Implications for Rhotics as a Class}

The results suggest a strong relationship between the acoustics of the rhotics as a group. F1 and F2 are almost identical in both dynamics and frequency for each place pair (e.g. $/ \mathrm{r} /$ and $/ \mathrm{R} / ; / \mathrm{r}^{\mathrm{j}} /$ and $/ \mathrm{R}^{\mathrm{j}} /$ ). Their data suggest some marginal difference in the height of the tongue body for $/ \mathrm{r} /$ and $/ \mathrm{R} /(/ \mathrm{R} /$ is somewhat lower $)$. This difference most likely has to do with the uvular and alveolar place distinctions. The dorsum is backed in the case of uvular rhotic and not raised quite as much as the tongue tip is raised to the alveolar ridge for the alveolar rhotic. The F2 results suggest no difference in frontness between $/ \mathrm{r}, \mathrm{R} /$. This result is unexpected given the different places of articulation. However, this effect is most likely due to the backed tongue dorsum which is characteristic of $/ \mathrm{r}$ / (Proctor, 2009; 2011). This suggests that there is a strong correlation between F2 and the backness of the tongue dorsum and that F2 is less affected by constrictions made in the anterior region of the mouth. $\mathrm{F} 2$ for $/ \mathrm{r}^{\mathrm{j}} /$ is somewhat lower than $/ \mathrm{R}^{\mathrm{j}} /$, which

Rhotics and Palatalization in Upper and Lower Sorbian
Phonetica 2018;75:132-150

DOI: $10.1159 / 000481783$
145 
suggests more advancement of the tongue body during $/ \mathrm{R}^{\mathrm{j}} /$ and may be a result of the already raised tongue body. The difference in frequency of F1 is also neutralized during the 2 rhotics when they are palatalized, which suggests that palatalization is realized in a similar way for both uvular and alveolar rhotics. To strengthen this claim, the formant dynamics of F2 and F3 are similar, suggesting that palatalization has a similar effect on the gestural coordination of rhotics.

F3 is a marked point of difference between the uvulars $(2,806 \mathrm{~Hz}$, raw average) and the alveolars $(2,221 \mathrm{~Hz}$, raw average). Alwan et al. (1997) suggest the low F3 for rhotics, observed by Delattre and Freeman (1968), is likely due to a large front cavity volume associated with a posterior oral constriction. Certainly, the uvular trill is expected to have a large front cavity volume due to the primarily posterior oral constriction; however, it presumably would lack a constriction in the front cavity. Stevens (1998) suggests that for the case of / / / there are additional contributions from a sublingual component. The drastic difference in F3 for both the uvular and the alveolar suggest that this is the case. This is largely because the tongue tip does not rise up to create a constriction for uvular rhotics (as in the case of the retroflex $/ \mathrm{I} /$ ), nor is the blade of the tongue expected to rise (as in the case of bunched /I/). This results in a higher F3 for the uvular than the alveolar. The uvular and alveolar rhotics do have similar formant trajectories even if the absolute values are different. Both of the palatalized trills, $/ \mathrm{r}^{\mathrm{j}}, \mathrm{R}^{\mathrm{j}} /$, also show similar formant trajectories for $\mathrm{F} 3$ even though the F3 is higher for $/ \mathrm{R}^{\mathrm{j}} \%$. The difference in F3 frequency and trajectory also suggests an overall difference in the vocal tract shapes between uvular and alveolar rhotics. The data also strongly support the rhotics as a natural class due to the similarity in dynamics and frequencies of the rhotics examined here. The temporal dynamics of $/ \mathrm{R}, \mathrm{r} /$ show similarity in the timing of the gestures associated with articulation. The similar formant frequencies and trajectories for F1 and the non-significant difference between the frequencies and trajectories for F2 suggest a strong perceptual similarity which could cause similar acoustic-perceptual mapping in the brain. To strengthen this analysis, both the uvular and alveolar rhotics appear to have the same effect on the following vowel, leading to a greater number of acoustic-perceptual cues to rhoticism. Both the uvular and alveolar also behave the same when secondary palatalization is applied. This results in similar formant frequencies and trajectories.

Taken together, the acoustics and dynamics of the uvular and alveolar rhotics suggest strong unity as a class of sounds. The data presented here suggest that Proctor's $(2009,2011)$ analysis of rhotics (and laterals) is on the correct path. A vocalic tongue dorsum gesture is coordinated with a consonantal gesture. In the case of the alveolars, it is an apical gesture and in the case of the uvulars, it is a tongue body gesture. Due to the fact that the tongue dorsum gesture is a key feature of rhotic production, secondary palatalization requires an out-of-sync phase relationship between the conflicting tongue dorsum gestures. Figure 5 shows the proposed gestural relationship between the consonantal and vocalic gestures for both $/ \mathrm{R} /$ and $/ \mathrm{R}^{\mathrm{j}} /$. In the case of $/ \mathrm{R} /$, both the tongue dorsum and the tongue body gestures are coordinated simultaneously in the representation. These consist of a vocalic tongue dorsum gesture in the pharynx, $\{\mathrm{WD}(\mathrm{pha})\}$, and a consonantal tongue body gesture at the uvular place, $\{$ NAR(uv) $\}$. However, in the case of $/ \mathrm{R}^{\mathrm{j}}$, there is a necessary phase difference between the palatal, \{NAR(uv-pal) and $\mathrm{OP}(\mathrm{pha}\}$, and the retracted position of the tongue dorsum for the rhotic production $\{\mathrm{WD}(\mathrm{pha})\} . \mathrm{WD}$, in this sense, represents vocalic gestures, where the closure is not tight enough to produce a closure or frication. NAR is used to represent consonantal 


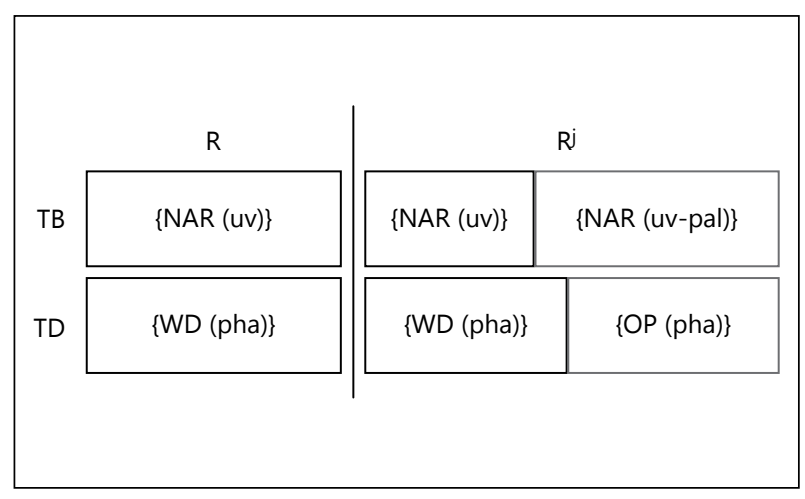

Fig. 5. Relatively in-sync coordination between the tongue body and tongue dorsum gestures for the production of $/ \mathrm{R} /$ (left). For $/ \mathrm{R}^{\mathrm{j} /}$ (right), there is a mismatch between the gestural coordination of the tongue body and tongue dorsum gestures (based on F2 and F2-F1 delays). As a result of conflicting demands, there is phase mismatch between the tongue dorsum retraction and palatalization gesture.

gestures with narrower constrictions than vocalic gestures. OP represents a controlled opening of width. For the palatalized rhotics, this consists of tongue dorsum advancement as a consequence of tongue body raising and fronting. The representation presented in Figure 5 is thus more generalizable to other rhotics in the sense that there is a tongue dorsum gesture in the pharynx coordinated with a consonantal gesture corresponding to the primary place of articulation, be that uvular or alveolar.

The inherent conflict between palatalization and rhotics can be seen in the representation as a mismatch in the timing of the two opposing gestures. Similar to the proposal of Kavitskaya et al. (2009) about the inherent articulatory conflict on the tongue dorsum, I suggest the out-of-phase relationship is responsible for the diachronic instability of palatalized rhotics. In languages like Slovenian where $/ \mathrm{r} / \mathrm{j}$ has been depalatalized to a sequence of $/ \mathrm{rj} /$ (Carlton, 1991), the gestural phase mismatch has caused the $/ \mathrm{r} /$ to be reinterpreted as 2 separate segments, causing the phase relationship between the tongue dorsum and tongue body gestures to realign. The vocalic dorsal component also explains the phototactic patterning of rhotics across the languages of the world: rhotics most typically occur adjacent to the syllable nucleus (or as the syllable nucleus). Coordination of this vocalic gesture is often phased towards the vocalic centre of a syllable (Gick et al., 2006) and as coordination of these gestures within a syllable is easier to achieve if rhotics are located adjacent to the syllable nucleus. However, further articulatory research is required to validate these claims.

Another interesting possibility is that Upper Sorbian speakers adopted the uvular rhotic from German because the formant frequencies are overall so similar to the alveolar rhotic. In a strongly mixed Sorbian/German-speaking environment, where the Upper Sorbian children are exposed to German on a daily basis, the similarity between the 2 could have easily caused a merger in the phonetic inventory of the children. This would also explain why speakers of Russian (Kornev, 2013), Czech (Howson et al., 2014), and other languages with alveolar trills who cannot make them often substitute the alveolar rhotic with a uvular rhotic (this is typically considered a speech disorder).

Finally, the results call into question whether F3 is the distinguishing factor separating rhotics and laterals. F3 was only found to be consistently lower than /1/ for /r/ and lower for $/ \mathrm{R} /$ during some time points over the course of articulation; furthermore, palatalization neutralized F3 differences during the articulation of the liquid for both the alveolar and the uvular palatalized rhotic; however, it should be noted that during much of the articulation of the palatalized alveolar rhotic, $/ \mathrm{r} /, \mathrm{F} 3$ is indeed lower than 
/1/ (see Fig. 2 for a comparison). Narayanan et al. (1999) suggest that at least 1 factor distinguishing rhotics and laterals may be the presence of antiformants for laterals but not rhotics. Although antiformants were not investigated here, the data presented at least suggest that something other than F3 may be contributing to the perceptual difference between rhotics and laterals.

\section{Conclusion}

This paper has presented an acoustic analysis of the liquids in Sorbian. Dynamic measures of Upper Sorbian $\left(/ R, R^{j}, 1 /\right)$ and Lower Sorbian $\left(/ r, r^{j}, 1 /\right)$ liquids were presented. The analysis methods allowed for a comparison of the different formant characteristics of many of the rhotics and laterals of Sorbian and their hypothesized articulatory correlates.

The data suggested that the inconsistency between palatalization and trills is not related to retraction of the tongue tip gesture caused by palatalization (Iskarous and Kavitskaya, 2010). Rather, the results suggest the inability to create proper tongue stability and the constant movement towards a palatal target likely interferes with the aerodynamic conditions necessary to produce trilling.

The rhotics as a class showed a striking similarity in both formant dynamics and frequencies, suggesting a strong similarity in the acoustic and perceptual qualities of the uvular and alveolar rhotics. The similarity in F2 also suggests that the activity of the tongue dorsum is similar between the uvular and alveolar rhotics. Palatalization also exhibited the same formant effects on both the uvular and alveolar rhotics. F3, however, is not the most reliable distinguisher of the rhotic. F3 of the alveolar trill is characteristically low because of the alveolar and dorsal constrictions which conspire to lower the F3. The uvular trill lacks the alveolar gesture, which causes F3 to be much higher and only significantly different from $/ 1$ / for an extremely short duration of time (the absolute value of the difference of the means is also quite small). F2 is a much more reliable indicator of rhotic classhood. The effect of palatalization on F2 was a delayed increase, which suggests it is possible that the delay in F2 increase is a way to maximize the perceptual salience of the palatalized rhotics.

The data do suggest that tongue dorsum activity is a consistent active articulator across rhotics, even for alveolar and uvular places. This suggests that Proctor's $(2009,2011)$ assertion that rhotics are composed of the coordination of a tongue tip and tongue dorsum gesture is on the right track. Rather, it could be restated to rhotics being composed of a consonantal gesture and a vocalic dorsal gesture. In the case of apical rhotics, the consonantal gesture involves the tongue tip, but in the case of the uvular ones, it involves the tongue body. This composition also explains some of the phonological patterning observed for rhotics such as syllable position and the avoidance of rhotics and high vocoids. However, further articulatory work is needed to validate these claims.

However, the data set does consist of a small number of tokens and environments. More data collection with both rhotics in different environments and with more tokens would allow more significant generalizations to be made. Vocal tract differences between the Upper and Lower Sorbian speakers do make a direct comparison of the uvular and alveolar rhotics more difficult. Normalization methods were used in order to control for this as much as possible, but this is still an issue to some extent. Finally, 
cross-linguistically, the class of rhotics is much larger than the data presented here, including fricatives. Thus, to make stronger generalizations about the class of rhotics larger data sets with more rhotics must be examined.

\section{Acknowledgements}

I would like to thank Dr. Kochetov, Dr. Wornar, and Dr. Jocz for their advice during the planning stages of this research and for help finding research participants. I would also like to thank Dr. Grawunder, Dr. Lancia, Dr. Comrie, the staff at the Max Planck Institute for Evolutionary Biology, and the staff at the Sorbian institute for making me feel at home and allowing me to use their facilities for my data recording. Finally, I would like to thank the reviewers for their helpful comments. This research was funded by the Germany/Europe Fund granted by the University of Toronto and SSHRC\#771-2015-0048.

\section{Disclosure Statement}

I declare there were no conflicts of interest during data collection, analysis, or publication of this article.

\section{References}

Adank P, Smits R, van Hout R (2004): A comparison of vowel normalization procedures for language variation research. J Acoust Soc Am 116:3099-3107.

Alwan A, Narayanan S, Haker K (1997): Toward articulatory-acoustic models for liquid approximants based on MRI and EPG data. II. The rhotics. J Acoust Soc Am 101:1078-1089.

Boersma P, Weenink D (2011): Praat: doing phonetics by computer (computer program). Version 5.3.65. http:// www.praat.org/.

Bolla K (1981): A Conspectus of Russian Speech Sounds. Cologne, Böhlau.

Browman CP, Goldstein LM (1995): Dynamic modeling of phonetic structure; in Fromkin VA (ed): Phonetic Linguistics. Essays in Honor of Peter Ladefoged. Orlando, Academic Press, pp 35-53.

Catford JC (1988): A Practical Introduction to Phonetics. Oxford, Clarendon Press.

Carlton TR (1991): Introduction to the Phonological History of the Slavic Languages. Bloomington, Slavica Publishers.

Davidson L (2006): Comparing tongue shapes from ultrasound imaging using smoothing spline and analysis of variance. J Acoust Soc Am 120:407-415.

Delattre P (1971): Pharyngeal features in the consonants of Arabic, German, Spanish, French, and American English. Phonetica 23:129-155.

Delattre P, Freeman DC (1968): A dialect study of American r's by X-ray motion picture. Linguistics 44:2968.

Engstrand O, Frid J, Lindblom B (2007): A perceptual bridge between coronal and dorsal /r/; in Sole MJ, Beddor PS, Ohala M (eds): Experimental Approaches to Phonology. Oxford, OUP, pp 175-191.

Fant G (1960): Acoustic Theory of Speech Production. The Hague, Mouton.

Gick B, Campbell F, Oh S, Tamburri-Watt L (2006): Towards universals in the gestural organization of syllables. A cross-linguistic study of liquids. J Phon 34:49-72.

Gu C (2002): Smoothing Spline ANOVA Models. New York, Springer.

Hall TA (2000): Typological generalizations concerning secondary palatalization. Lingua 110:1-25.

Hall TA, Hamann S (2010): On the cross-linguistic avoidance of rhotic plus high front vocoid sequences. Lingua 120:1821-1844.

Heselwood B (2009): Rhoticity without F3: lowpass filtering, F1-F2 relations and the perception of rhoticity in the "north-force," "start" and "nurse" words. Leeds Working Pap Ling Phon 14:49-64.

Howson P (2017): Upper Sorbian. J Int Phon Assoc 28:1-9.

Howson P, Komova K, Gick B (2014): Czech trills revisited: an ultrasound EGG and acoustic study. J Int Phon Assoc 44:115-132.

Iskarous K, Kavitskaya D (2010): The interaction between contrast, prosody, and coarticulation in structuring phonetic variability. J Phon 38:625-639.

Rhotics and Palatalization in Upper and Lower Sorbian
Phonetica 2018;75:132-150

DOI: $10.1159 / 000481783$ 
Jocz L (2013): Studien zum obersorbischen und kaschubischen Konsonantismus mit einer vergleichenden Analyse [A study of Upper Sorbian and Kashuban consonants with a comparative analysis]. Leipzig, Institute for Sorbian, University of Leipzig.

Kavitskaya D, Iskarous K, Noiray A, Proctor M (2009): Trills and palatalization: consequences for sound change; in Reich J, Babyonyshev M, Kavitskaya D (eds): Proceedings of the Formal Approaches to Slavic Linguistics 17. Ann Arbor, Michigan Slavic Publications, pp 97-110.

Knight R, Dalcher C, Jones M (2007): A real-time case study of rhotic acquisition in Southern British English. Proceedings of the 16th International Congress on Phonetic Sciences, Saarbrücken, pp 1581-1584.

Kochetov A (2005): Phonetic sources of phonological asymmetries: Russian laterals and rhotics. Proceedings of the 2005 Canadian Linguistics Association Annual Conference, Western Ontario University, London, pp 1-12.

Kochetov A, Howson P (2015): On the incompatibility of trilling and palatalization: a single-subject study of sustained apical and uvular trills. Proceedings of Interspeech 2015, Dresden, pp 2187-2191.

Kornev A (2013): Articulation disorders in Russian-speaking children: reconsidering the concept of "developmental verbal/articulatory apraxia of speech." St Petersburg State Pediatric Medical Academy.

Ladefoged P, Maddieson I (1996): The Sounds of the World's Languages. Oxford, Blackwell.

Lindau M (1985): The story of /r/; in Fromkin V (ed): Phonetic Linguistics. Essays in Honor of Peter Ladefoged. Orlando, Academic Press, pp 157-168.

Lindblom B (1963): Spectrographic study of vowel reduction. J Acoust Soc Am 35:1773-1781.

Lobanov BM (1971): Classification of Russian vowels spoken by different listeners. J Acoust Soc Am 49:606-608.

Maddieson I (1984): Patterns of Sounds. Cambridge, Cambridge University Press.

McGowan R (1992): Tongue-tip trills and vocal-tract wall compliance. J Acoust Soc Am 91:2903-2910.

Mielke J (2011): An articulatory study of rhotic vowels in Canadian French. Can Acoust 39:164-165.

Moseley C (2012): The UNESCO Atlas of the World's Languages in Danger: Context and Process. World Oral Literature Project Occasional paper 5. Cambridge, University of Cambridge.

Narayanan S, Byrd D, Kaun A (1999): Geometry, kinematics, and acoustics of Tamil liquid consonants. J Acoust Soc Am 106:1993-2007.

Proctor M (2009): Gestural Characterization of a Phonological Class: The Liquids; dissertation, Yale University, New Haven.

Proctor M (2011): Towards a gestural characterization of liquids: evidence from Spanish and Russian. J Lab Phonol 2:451-485.

Recasens D (1991): On the production characteristics of apicoalveolar taps and trills. J Phon 19:267-280.

Recasens D, Pallarès MD (1999): A study of /flap/ and /r/ in the light of the "DAC" coarticulation model. J Phon 27:143-169.

R Development Core Team (2016): R: a language and environment for statistical computing. http://www.R-project. org/.

Schaarschmidt G (1998): A Historical Phonology of Upper and Lower Sorbian Languages. Heidelberg, Winter.

Solé MJ (2002): Aerodynamic characteristics of trills and phonological patterning. J Phon 30:655-688.

Spajić S, Ladefoged P, Bhaskararao P (1996): The trills of Toda. J Int Phon Assoc 26:1-21.

Sproat R, Fujimura O (1993): Allophonic variation in English /1/ and its implications for phonetic implementation. J Phon 21:291-311.

Stevens KN (1998): Acoustic Phonetics. Cambridge, MIT Press.

Stoll T, Harrington J, Hoole P (2016): Intergestural organisation and CV-overlap in palatalised liquids in Russian. Proceedings of the International Congress of Phonetic Sciences, Glasgow, pp 1-4.

Stone G (1993): Sorbian (Upper and Lower); in Comrie B, Corbett G (eds): The Slavonic Languages. London, Routledge, pp 759-794.

Thomas ER, Kendall T (2007): NORM: the vowel normalization and plotting suite. http://ncslaap.lib.ncsu.edu/ tools/norm/

Westbury JR, Hashi M, Lindstrom MJ (1995): Differences among speakers in articulation of American English /r/: an X-ray microbeam study. Proceedings of the International Conference on Spoken Language Processing, Stockholm, pp 797-800.

Wiese R (2001): The phonology of /r/; in Hall TA (ed): Distinctive Feature Theory. Berlin, Mouton de Gruyter, pp 335-368.

Wornar E (2007): Jezykłuzycki; in Sawicka, I. (ed): Komparacja wspłoczesnych jezyków słowianskich. Fonetyka. Fonologia. Opole, Instytut Filologi Polskiej, pp 321-330. 